\title{
Denovo Designing, Virtual Screening and Lead Optimization of Potential Drug Candidate for Herpes Disease
}

\author{
Monica Sharma ${ }^{1,2 *}$, Puneet Rawat ${ }^{2}$ and Ankita Mehta ${ }^{2}$
}

${ }^{1}$ Department of Biotechnology, School of Biosciences and Biotechnology, Babasaheb Bhimrao Ambedkar University, Vidya Vihar, Raebareli Road, Lucknow, Uttar Pradesh, India

${ }^{2}$ Department of Biotechnology, Delhi Technological University, Main Bawana Road, Shahbad Daulatpur, Delhi, India

\begin{abstract}
Herpes simplex virus (HSV1, HSV 2) is a neurotropic and neuroinvasive virus which becomes latent and causes a lifelong infection. HSV-1 and 2 produce infected cell protein (ICP)- 47 against MHC class I antigen presentation pathway by inhibiting the transporter associated with antigen processing (TAP). ICP 47 is also responsible for evasive nature of HSV in human immune system. Currently available antiviral drugs and vaccines only slowdowns the infection but it does not cure the infection. In present study, we have in silico designed a potential drug candidate against HSV ICP-47 target through de-novo pathway using eLEA3D. The derived ligand docked with the natural viral receptor ICP-47 showed the binding affinity of -4.07 , but it was found toxic in FAF DRUG online ADMET tool, due to presence of high risk imine group. Further manual optimization led to generation of many bioisosteres and final lead structure showed no toxicity and a high binding affinity of -7.53 . Our designed lead can act as a potential therapeutic compound against HSV.
\end{abstract}

Keywords: HSV; ICP-47; eLEA3D; Denovo designing; Bioisosteres

\section{Introduction}

Herpes simplex viruses (HSV) 1 and 2, the members of herpes virus family Herpesviridae are ubiquitous, highly contigious agents which infect humans [1,2]. They cause cold sores, herpetic keratitis and genital herpes [3-5]. An estimated 400 million people worldwide are currently infected by HSV-2 and infection of HSV-1 is spreading to developed regions like USA, Western Europe, Australia and New Zealand [WHO Fact Sheet, 2015]. HSV-1 persists in the body in dormant state by escaping the immune system and results in sporadic viral reactivation [6].

HSV evades the immune system by interfering with MHC Class I antigen presentation on the cell surface. Infected cell protein (ICP) 47 caused major histocompatibility complex (MHC) class I proteins retaintion in the endoplasmic reticulum (ER). MHC presents the antigen to $\mathrm{CD}^{+} 8 \mathrm{~T}$ cells that are inhibited after expression of ICP 47 in the cell [7]. ICP 47 blocks peptide (viral epitope) transport across the ER membrane by transporter associated with antigen processing (TAP) $[8,9]$ so that MHC class I proteins remain in ER without peptides and cytotoxic T- lymphocytes activation can be stopped. This allows virus to reside for a protracted period in the host.

Due to serious threat to human population a proper treatment and cure of HSV is required. For last two decades HSV glycoprotein D, has been the predominant HSV vaccine candidate $[10,11]$, but the outcome of clinical trials of the vaccine have been really disappointing [12]. Antiviral drugs (valacyclovir, acyclovir, famciclovir, etc.) used against HSV infection, inhibit DNA polymerases and slows down infection by reducing viral replication but does not cure the infection completely [13]. Inappropriate prescribing and wide spread uncontrolled use of antiviral drugs led to emergence of resistance in the viruses. Recently, it has been observed that natural serine protease inhibitor (serpins) like serpinantithrombin III (AT III) inhibit HSV infection during an entry event. Antithrombin III demonstrated a promising result at experimental levels but yet it is far from any therapeutic use [13,14].

Due to inaccessibility of any effective drug and vaccine there is therefore, an urgent need for an effective HSV vaccine or drug that provides protection against infection and also thwart the virus entering a latent state [15]. Computer aided drug discovery design (CADD) has emerged as a way to significantly decrease compounds screening while retaining same level of lead compound discovery at the same time [16]. In the present manuscript we have designed lead compound by denovo designing strategy and molecule having highest score was further optimized by virtual screening to increase its affinity to target and reduce toxicity by toxicological analysis by online ADMET profiling tools of FAF DRUG 20 online tool and ORISIS data warrior.

\section{Methodology}

\section{Sequence retrival}

DNA sequence of ICP-47 of HSV-2 was retrieved from NCBI and it was blasted to human genomic and transcriptomic database. The structure of target protein ICP-47 was retrieved from rcsb.org in PDB (text) format (PDB I.D. 1QLO).

\section{Denovo drug designing}

After exhaustive literature survey and database searching, no ligand was found that bind to this target, so automated de-novo drug design strategy was adopted to get a hit molecule. eLEA3D program was used for denovo generation of ligand, which create new molecules by using a library of molecular fragments and by determining best combinations of molecular fragments that fit user-defined physicochemical properties

*Corresponding authors: Monica Sharma, Department of Biotechnology, Delh Technological University, Main Bawana Road, Shahbad Daulatpur, Delhi, India, Tel: +91-9717386785; E-mail: monashimla@gmail.com

Received September 26, 2015; Accepted October 17, 2015; Published October 24, 2015

Citation: Sharma M, Rawat P, Mehta A(2015) Denovo Designing, Virtual Screening and Lead Optimization of Potential Drug Candidate for Herpes Disease. J Microb Biochem Technol 7: 367-373. doi:10.4172/1948-5948.1000240

Copyright: (c) 2015 Sharma M, et al. This is an open-access article distributed under the terms of the Creative Commons Attribution License, which permits unrestricted use, distribution, and reproduction in any medium, provided the original author and source are credited. 
(also called constraint function) [17]. For De-novo ligand design, PDB structure of the target protein is uploaded in the server. Binding site for the ligand is set around 17th residue (Valine) with the binding site radius of 10 angstrom. Weight in the final score and conformational search for the given ligand was set to one, also ionization of carboxylates, phosphates, and guanidiniums was allowed.

\section{Autodocking and toxicity profiling}

The resulting ligand was docked with natural viral receptor ICP-47 in Autodock4 [18] and toxicity profiling was done with FAF DRUG 2.0 online ADMET tool [19]. To increase its binding affinity and reduce toxicity we manually optimize the ligand by virtual combinatorial ligand optimization. The members of each class of substituent were numerated and combinatorially combined to create bioisosteres. Each functional group replacement was docked against the ICP-47 receptor taking other functional groups constant to check whether they are positively affecting the binding affinity and ADMET prolife is also studied simultaneously. Threshold binding energy value is set to -4.11 . All functional group possessing binding energy less than -4.11 were selected for further optimization by OVAT (One Variable at a time) method and progressive method.

\section{Results}

The blast search of the DNA sequence was performed to see whether ICP-47 of HSV showed any similarity with the human or not and it did not show significant similarity to any of the DNA/ protein sequence. Firstly, the available chemical databases were screening for their binding to the HSV ICP-47 (PDB I.D.-1QLO). No ligand was observed which had the binding affinity to target protein. Hence, automated denovo drug design strategy was adopted to get a hit molecule.

eLEA3D (Ligand by Evolutionary Algorithm) programme was

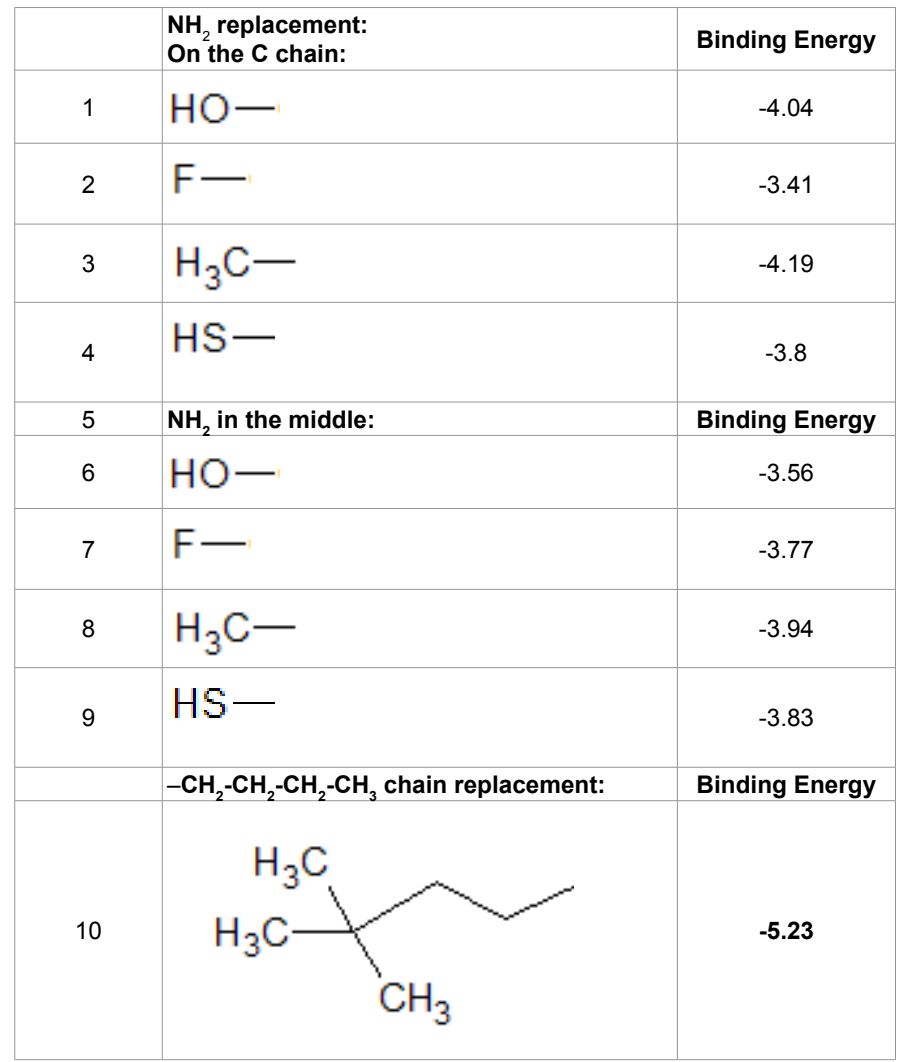

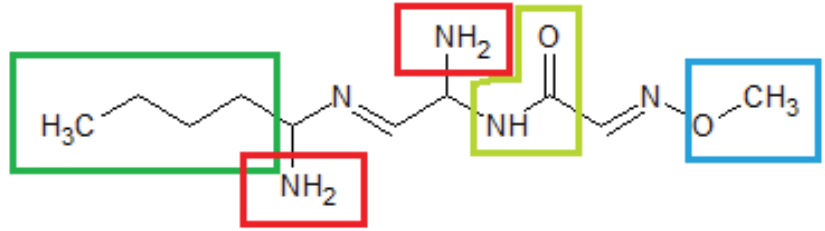

Figure 1: Denovo generated Ligand (eLEA3D) with all the replaceable functional groups.

used for the de novo generation of the ligand was based on genetic algorithm that evolves the molecular structures generation after generation until the appearance of fitted molecules [17]. Each molecule of each generation is evaluated by fitness function (constraints) which is either molecular properties or an affinity prediction by a docking program. Submitting the query generated 10 structures of possible lead molecule along with their scores. The best structure had a maximum scoring percentage of $71.46 \%$ (Figure 1). Rest structures had the scoring percentage of 50 and hence only first result was chosen as a lead molecule for further steps.

De-Novo designed lead molecule was further docked with ICP47 and analyzed with FAF DRUG 2.0 ADMET tool. Lead molecule showed a binding affinity of -4.07 and a high risk of toxicity due to presence of imine group.

To increase binding affinity and reduce toxicity, lead compound was optimized manually by combinatorial optimization method. Due to small size of lead molecule it became possible to mark all replaceable functional groups and substitute with similar functional groups to create bioisosteres [20]. Each functional group replacement was docked with ICP-47. Out of total 57 replacements of functional groups,

12 (112)




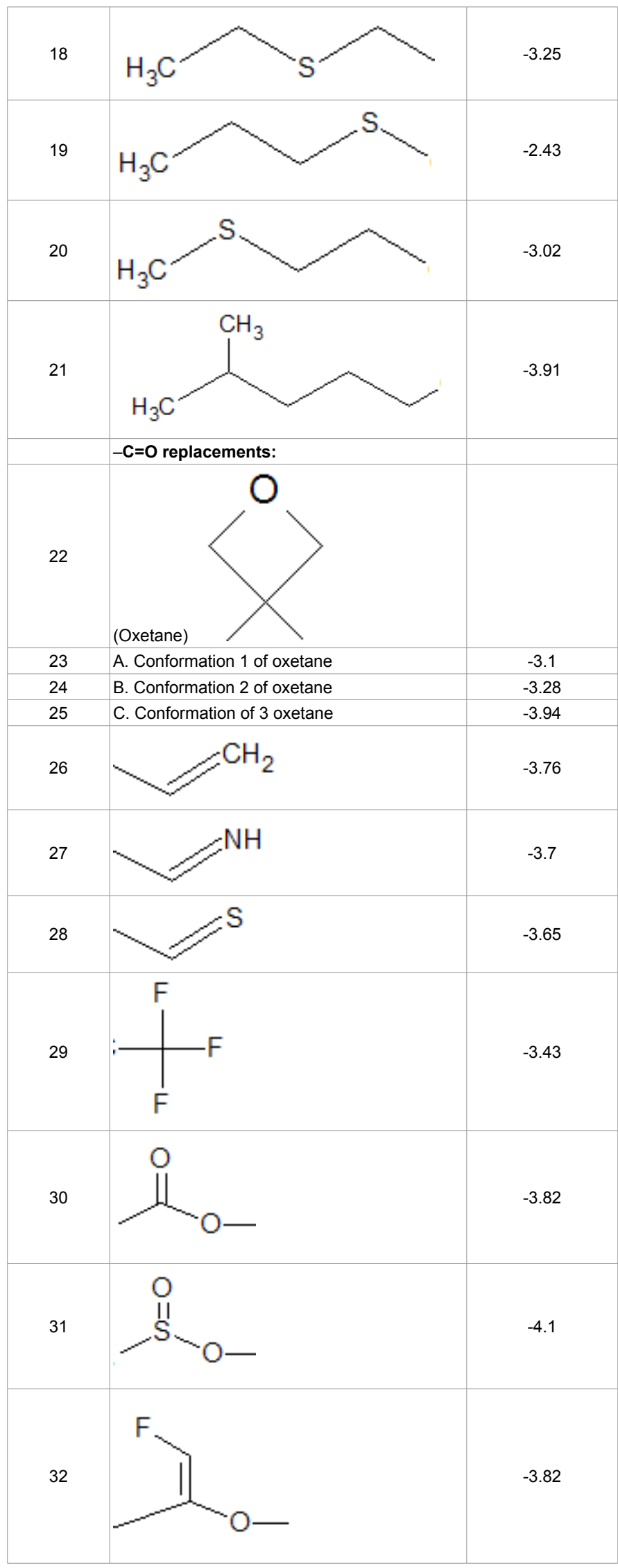

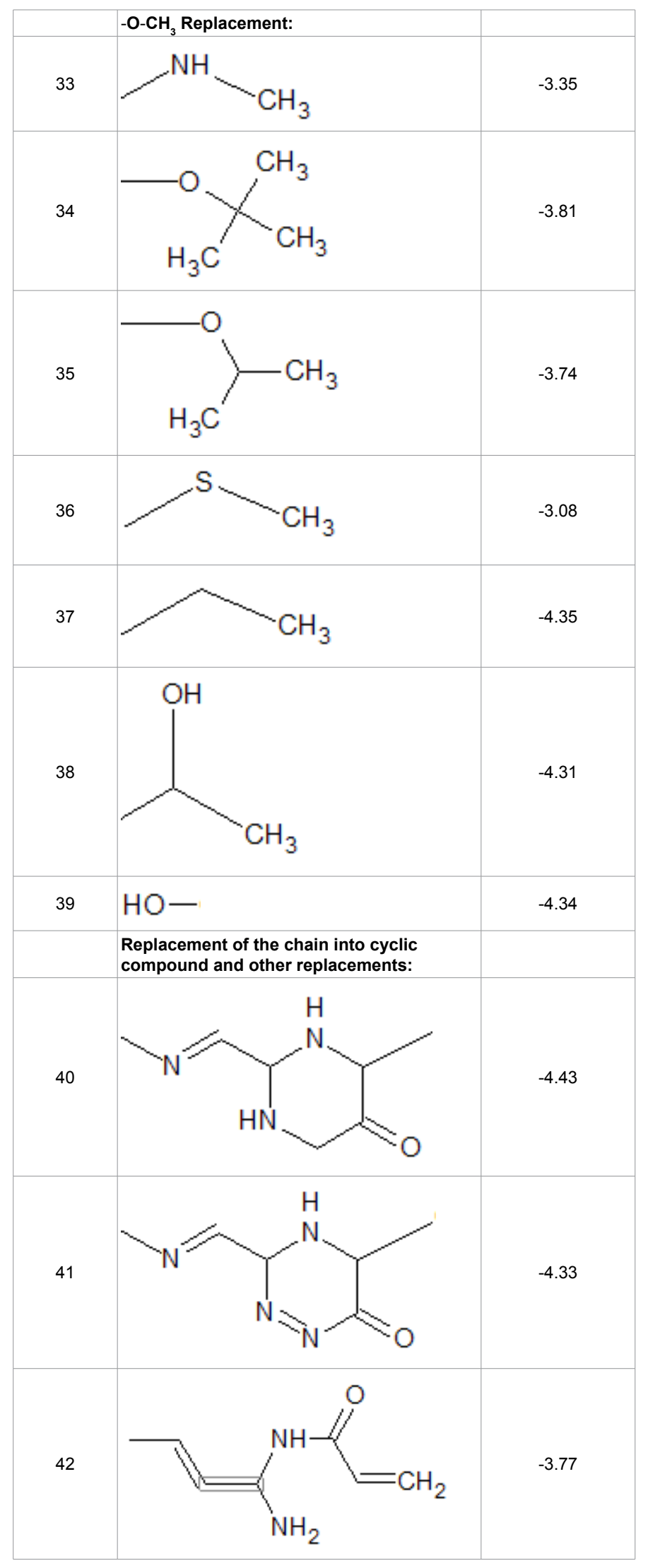




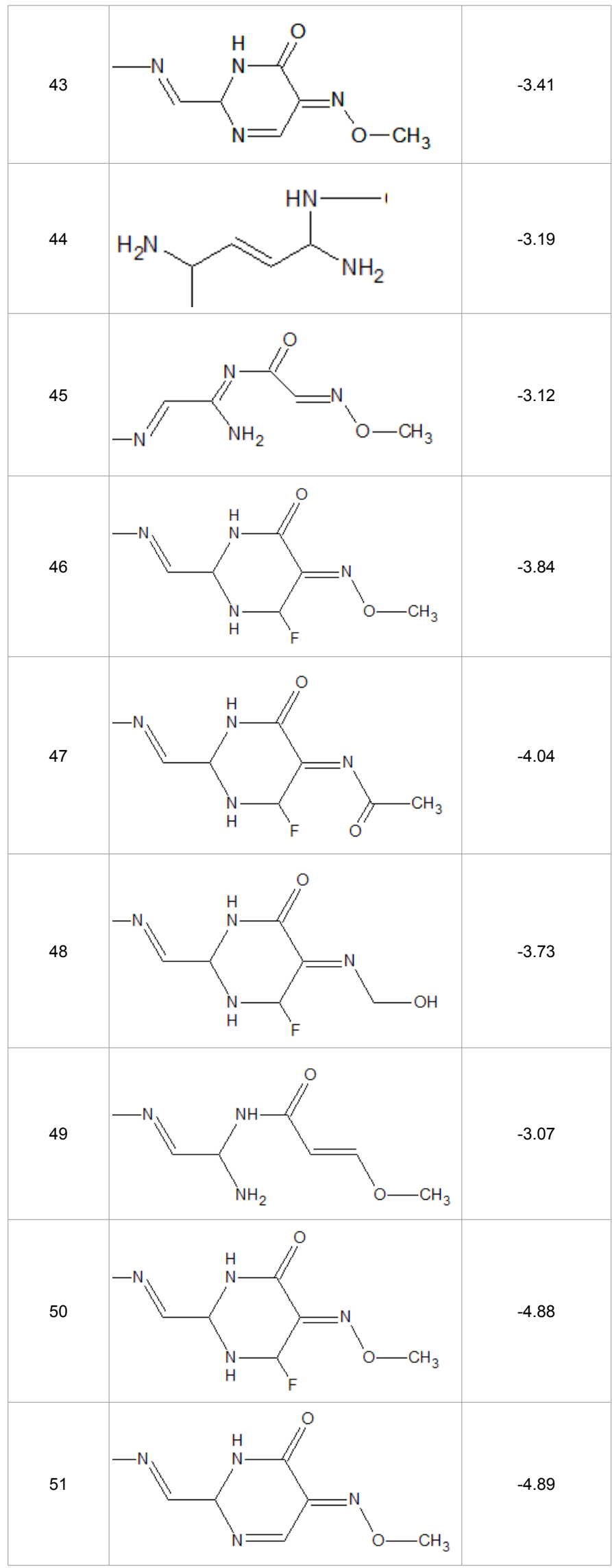

\begin{tabular}{|c|c|c|}
\hline & $\mathrm{CONH}_{2}$ Replacement: & \\
\hline 52 & & -2.71 \\
\hline 53 & & -3.76 \\
\hline 54 & & -4.26 \\
\hline 55 & & -3.75 \\
\hline 56 & & -3.06 \\
\hline 57 & & -4.37 \\
\hline & & \\
\hline
\end{tabular}

Table 1: All the functional group replacements of de-novo designed ligand and their binding affinity with ICP-47.

10 functional group were selected having better value than threshold of -4.11(Table 1). $\mathrm{NH}_{2}$ functional group has only one better replacement $\left(-\mathrm{CH}_{3}\right)$, so we replaced it in all further structural analysis, for the other 9 passed groups exhibiting binding energy $>-4.11$ (Figure 2), the OVAT method was utilized and docking with ICP-47 and ADMET profile was simultaneously studied (Table 2). Total 24 iterations were performed which showed promising results with top binding energy of -7.16, -6.6, -6.57 but toxicity still persisted (Table 3 ).

On analysis it is found that toxicity was being caused by the nitrogen ring replacement, so progressive method was used to generate structure excluding the ring replacements. This gave the best result of -5.96 but the toxicity was still there (Figure 2). To remove toxicity, $\mathrm{N}$ atoms of the ligand with the best binding energy $(-7.16)$ were replaced by carbon one at a time and ADMET profiling was done by FAF DRUG 2.0 until any non- toxic ligand was generated. So it would be much close to natural biological compounds and toxicity of imine group and azo group can be removed.

It was further docked in Autodock 4 and finally a non-toxic lead molecule having binding energy of -7.53 (Figures 3 and 4 ) was obtained. The toxicity of the lead molecule is checked with FAF Drug 2.0 which categorized it non-toxic (Figure 5). Toxicity was also crosschecked with help of ORISIS data warrior which categorized final lead molecule as an irritant. The lead molecule is also checked for binding with any receptor 


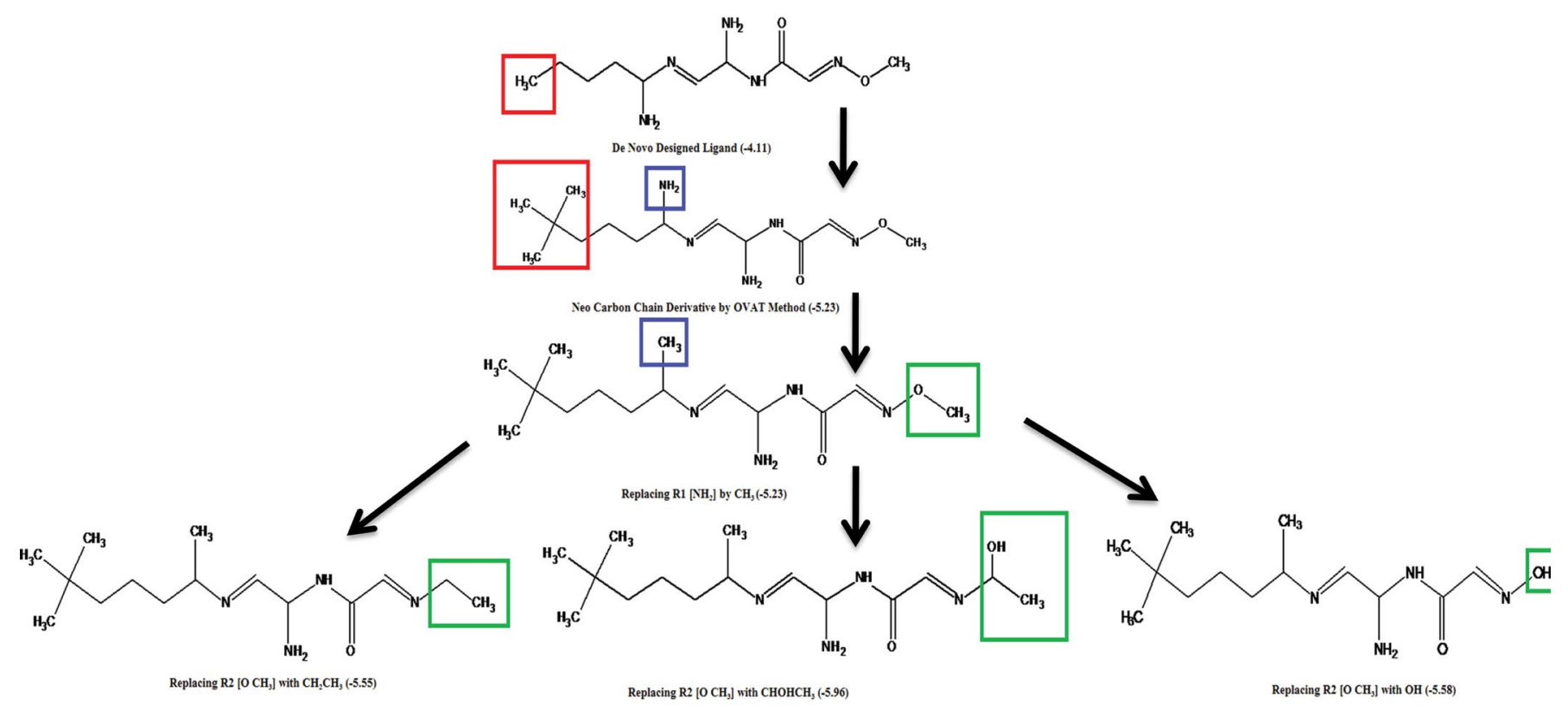

Figure 2: Progressive method optimization of the ligand with ICP-47 receptor of HSV virus with their binding energy.

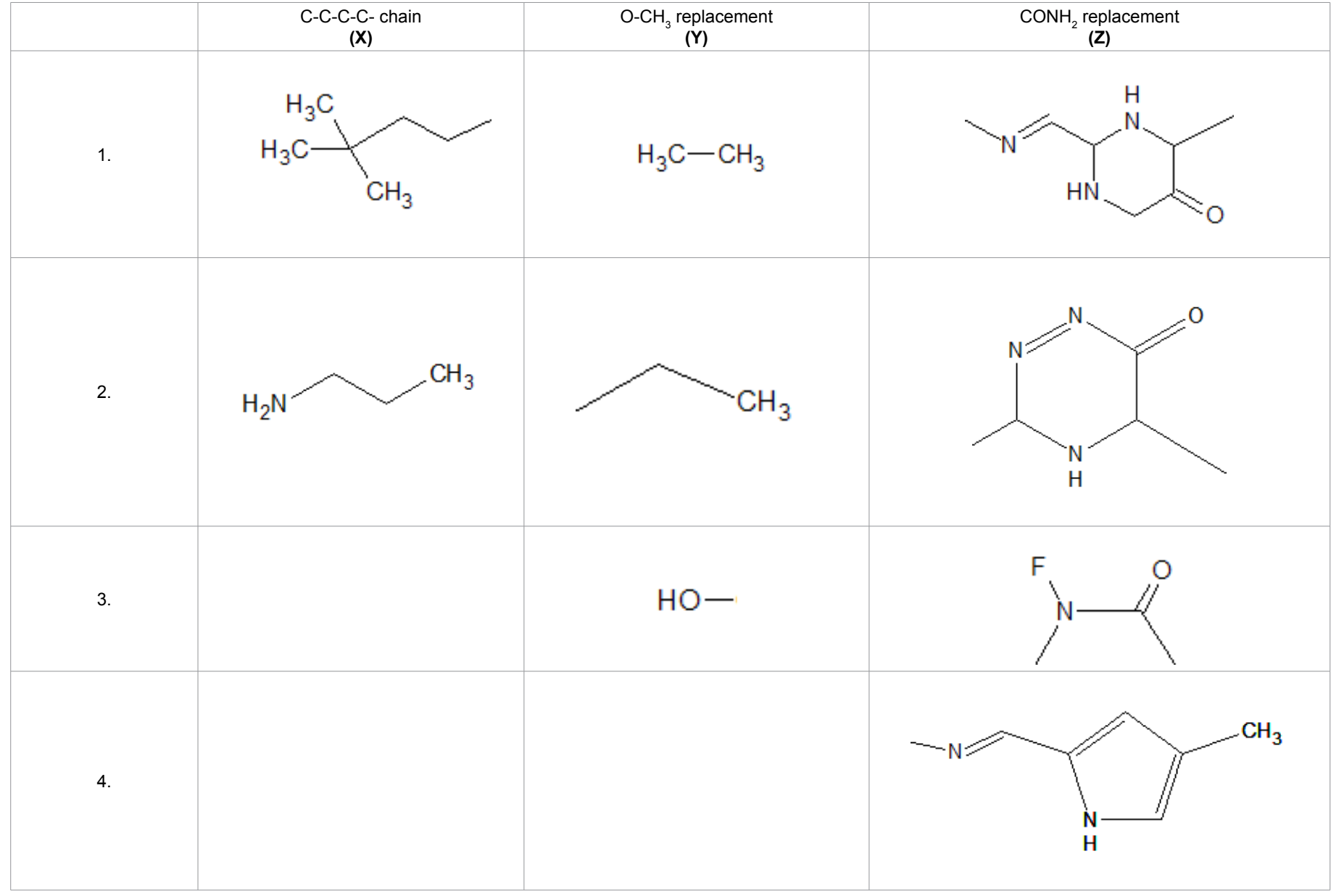

Table 2: All the passed functional group replacements for OVAT analysis. 


\begin{tabular}{|c|c|c|c|c|c|}
\hline S.No. & $\begin{array}{l}\text { Combination of } \\
\text { functional group }\end{array}$ & Binding energy & S. No. & $\begin{array}{l}\text { Combination of } \\
\text { functional group }\end{array}$ & $\begin{array}{l}\text { Binding } \\
\text { energy }\end{array}$ \\
\hline 1 & X1Y1Z1 & -5.82 & 1. & $\mathrm{X} 2 \mathrm{Y} 1 \mathrm{Z1}$ & -5.06 \\
\hline 2 & $\mathrm{X} 1 \mathrm{Y} 1 \mathrm{Z2}$ & $-6.6(2)$ & 2. & $\mathrm{X} 2 \mathrm{Y} 1 \mathrm{Z2}$ & -5.52 \\
\hline 3 & X1Y1Z3 & -5.66 & 3. & $\mathrm{X} 2 \mathrm{Y} 1 \mathrm{Z3}$ & -5.15 \\
\hline 4 & X1Y1Z4 & -5.97 & 4. & $\mathrm{X} 2 \mathrm{Y} 1 \mathrm{Z4}$ & -5.07 \\
\hline 5 & X1Y1Z5 & -5.56 & 5. & X2Y1Z5 & -4.89 \\
\hline 6 & X1Y1Z6 & -5.72 & 6. & $\mathrm{X} 2 \mathrm{Y} 1 \mathrm{Z6}$ & -4.92 \\
\hline 1 & $\mathrm{X} 1 \mathrm{Y} 2 \mathrm{Z1}$ & -6.1 & 1. & $\mathrm{X} 2 \mathrm{Y} 2 \mathrm{Z} 1$ & -5.7 \\
\hline 2 & X1Y2Z2 & $-7.16(1)$ & 2. & $\mathrm{X} 2 \mathrm{Y} 2 \mathrm{Z} 2$ & -6.06 \\
\hline 3 & $\mathrm{X} 1 \mathrm{Y} 2 \mathrm{Z3}$ & -6.38 & 3. & $\mathrm{X} 2 \mathrm{Y} 2 \mathrm{Z3}$ & -5.53 \\
\hline 4 & $\mathrm{X} 1 \mathrm{Y} 2 \mathrm{Z} 4$ & $-6.57(3)$ & 4. & $\mathrm{X} 2 \mathrm{Y} 2 \mathrm{Z} 4$ & -5.81 \\
\hline 5 & X1Y2Z5 & -6.36 & 5. & X2Y2Z5 & -4.95 \\
\hline 6 & X1Y2Z6 & -5.8 & 6. & $\mathrm{X} 2 \mathrm{Y} 2 \mathrm{Z6}$ & -5.12 \\
\hline 1 & $\mathrm{X} 1 \mathrm{Y} 3 \mathrm{Z1}$ & $-6.49(5)$ & 1. & $\mathrm{X} 2 \mathrm{Y} 2 \mathrm{Z1}$ & -5.69 \\
\hline 2 & X1Y3Z2 & $-6.57(4)$ & 2. & X2Y2Z2 & -5.68 \\
\hline 3 & X1Y3Z3 & -5.96 & 3. & $\mathrm{X} 2 \mathrm{Y} 2 \mathrm{Z3}$ & -5.15 \\
\hline 4 & X1Y3Z4 & -6.28 & 4. & $\mathrm{X} 2 \mathrm{Y} 2 \mathrm{Z} 4$ & -5.35 \\
\hline 5 & X1Y3Z5 & -5.74 & 5. & X2Y2Z5 & -5.07 \\
\hline 6 & X1Y3Z6 & -5.78 & 6. & $\mathrm{X} 2 \mathrm{Y} 2 \mathrm{Z} 6$ & -4.81 \\
\hline
\end{tabular}

Table 3: Binding affinity of the iterations made from the table 2 with ICP-47 receptor (by OVAT method).

present in human or other organism with pharmmapper server [21]. It showed some significant binding with them. Some top results of binding were retinoic acid receptor (PDB ID- 3DZY), Medium-chain specific acyl-CoA dehydrogenase, mitochondrial (PBD ID- 3MDE) and Glutathione S-transferase A1 (PDB ID- 1PL1) with binding energy of $-6.39,-5.99,-7.58$, respectively.<smiles>CC(O)CCC1NC(CNC(C)CCCC(C)(C)C)NNC1=O</smiles>

Figure 3: Structure of the ligand with no toxicity and binding energy of-7.53.

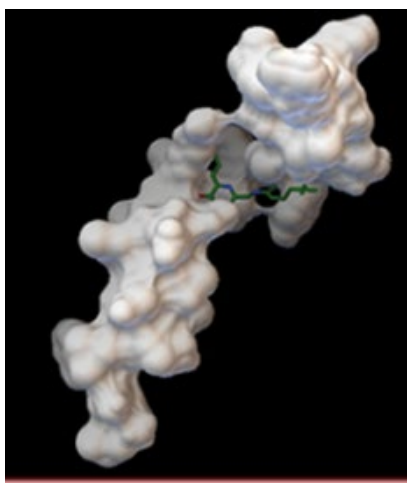

Figure 4: AUTODOCK4 results of binding of the potential drug candidate with ICP-47 receptor of Herpes virus.

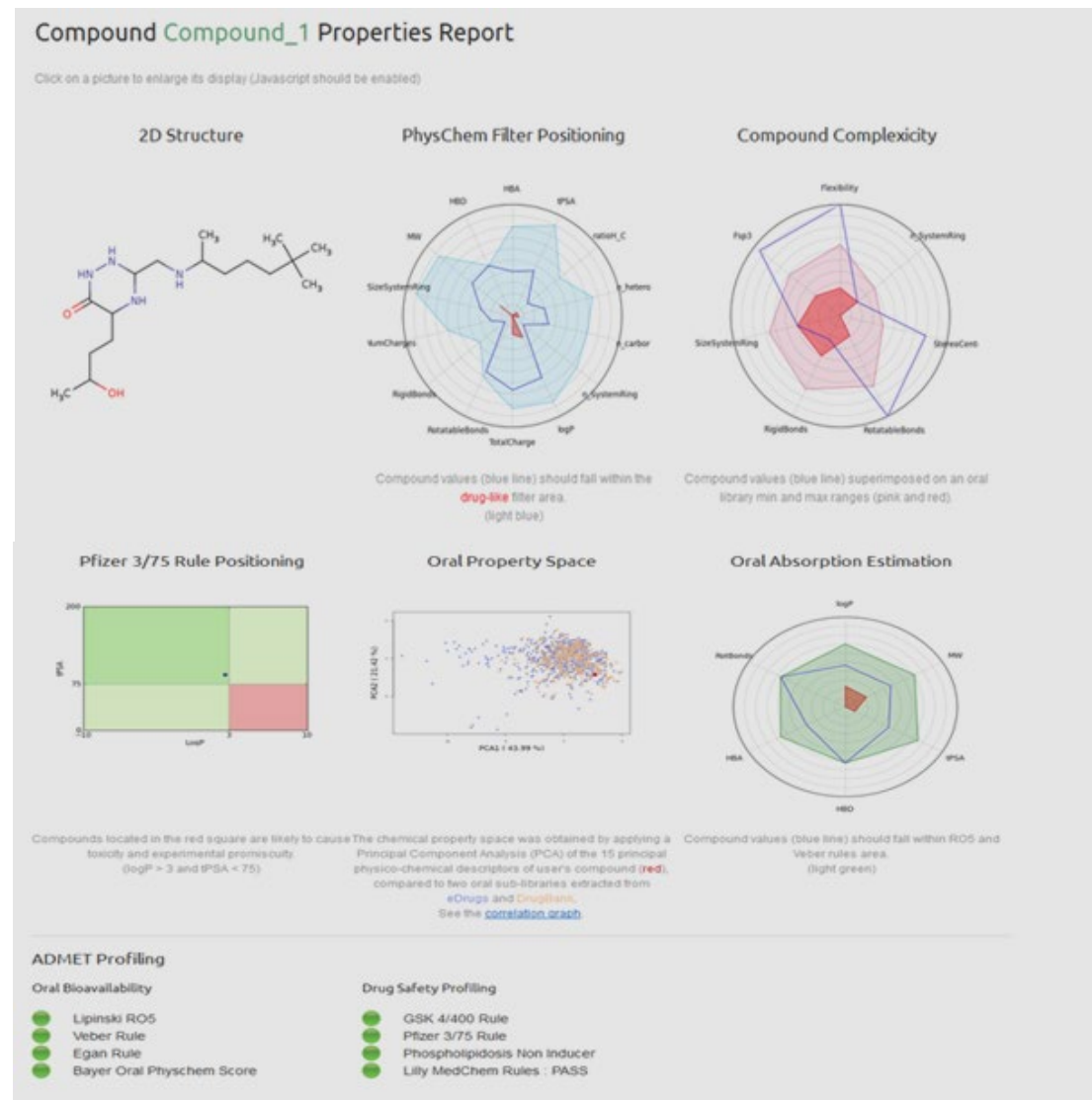

Figure 5: FAF DRUG 2.0 result of potential drug candidate. 
Citation: Sharma M, Rawat P, Mehta A (2015) Denovo Designing, Virtual Screening and Lead Optimization of Potential Drug Candidate for Herpes Disease. J Microb Biochem Technol 7: 367-373. doi:10.4172/1948-5948.1000240

\section{Discussion}

In recent years computer-aided drug design (CADD) approaches have revolutionized the field pharmaceutical research and many powerful standalone tools for CADD were developed, e.g., e-LEA3D, i Drug, iSMART etc. $[17,22,23]$. In these web servers many techniques were combined (pharmacophore mapping, similarity calculation, scoring, and target identification) to create a web interface which was more consistent and user friendly. Hartenfeller and Schneider have also emphasized that novel biologically active drug like lead molecules can be generated computationally on the basis of rule based fragment assembly [24]. Our initial hit molcule was also generated by fragment assembly method of e-LEA3D. Villoutreix et al.. also generated a non enzymatic tyrosine kinase inhibitors lead by virtual screening and its ADMET profiling was done with FAF Drug 2.0. These lead molecules can be used to discover potential Anti-Allergic drugs [25]. Similarly rational drug designing was used to generate many drug like molecules e.g. cimetidine (prototypical $\mathrm{H}_{2}$-receptor antagonist) [26], enfuvirtide[27], nonbenzodiazepines [28] and raltegravir [29].

\section{Conclusion}

The lead molecule generated by the procedure can be checked for it chemical synthesizability and can checked for its in vivo ADMET profiling in clinical trials. Its biding with other receptors can be further analysed to access its pharmaceutical potential in other diseases. Denovo drug design and virtual lead optimization and in vitro screening can further lead to decrease the timeline of any drug development and hence holds true potential in modern pharmacology and rational drug design.

\section{References}

1. Roizman B, Pellett PE (2001) The Family Herpesviridae: A Brief Introduction. In: Knipe DM, Howley PM, Fields Virology (4th edn) Lippincott, Williams and Wilkins, Philadelphia

2. Schiffer JT, Mayer BT, Fong Y, Swan DA, Wald A (2014) Herpes simplex virus-2 transmission probability estimates based on quantity of viral shedding. J R Soc Interface 11: 20140160.

3. Kaye S, Choudhary A (2006) Herpes simplex keratitis. Prog Retin Eye Res 25: 355-380.

4. Holdeman NR (2005) Herpes simplex virus: ocular manifestations; in Ocular therapeutics handbook: A clinical manual $\left(2^{\text {nd }}\right.$ edn) Lippincott Williams \& Wilkins, Philadelphia.

5. Choudhary A, Higgins G, Kaye SB (2008) Herpes simplex keratitis and related syndromes; in Cornea and external eye disease. Springer.

6. Hunsperger EA, Wilcox CL (2003) Capsaicin-induced reactivation of latent herpes simplex virus type 1 in sensory neurons in culture. J Gen Virol 84: 1071 1078.

7. York IA, Roop C, Andrews DW, Riddell SR, Graham FL, et al. (1994) A cytosolic herpes simplex virus protein inhibits antigen presentation to CD8+ T lymphocytes. Cell 77: 525-535.

8. Früh K, Ahn K, Djaballah H, Sempé P, van Endert PM, et al. (1995) A vira inhibitor of peptide transporters for antigen presentation. Nature 375: 415-418.

9. Hill A, Jugovic P, York I, Russ G, Bennink J, et al. (1995) Herpes simplex virus turns off the TAP to evade host immunity. Nature 375: 411-415.

10. Shin H, Iwasaki A (2013) Generating protective immunity against genital herpes. Trends Immunol 34: 487-494.
11. Awasthi S, Friedman HM (2014) Status of prophylactic and therapeutic genital herpes vaccines. Curr Opin Virol 6: 6-12.

12. Belshe RB, Leone PA, Bernstein DI, Wald A, Levin MJ, et al. (2012) Efficacy results of a trial of a herpes simplex vaccine. N Engl J Med 366: 34-43.

13. Knight DA, Hejmanowski AQ, Dierksheide JE, Williams JW, Chong AS et al. (2001) Inhibition of herpes simplex virus type 1 by the experimental immunosuppressive agent leflunomide. Transplantation 71: 170-174.

14. Whitney JB, Asmal M, Geiben-Lynn R (2011) Serpin induced antiviral activity of prostaglandin synthetase-2 against HIV-1 replication. PLoS One 6: e18589.

15. Bolland S, Pierce SK (2015) Ups and downs in the search for a Herpes simplex virus vaccine. Elife 4

16. Sliwoski G, Kothiwale S, Meiler J, Lowe EW Jr (2013) Computational methods in drug discovery. Pharmacol Rev 66: 334-395.

17. Douguet D (2010) e-LEA3D: a computational-aided drug design web server. Nucleic Acids Res 38: W615-621.

18. Morris GM, Huey R, Lindstrom W, Sanner MF, Belew RK, et al. (2009) AutoDock4 and AutoDockTools4: Automated docking with selective receptor flexibility. J Comput Chem 30: 2785-2791.

19. Lagorce D, Sperandio O, Galons H, Miteva MA, Villoutreix BO (2008) FAFDrugs2: free ADME/tox filtering tool to assist drug discovery and chemical biology projects. BMC Bioinformatics 9: 396.

20. Yuya Morita (2012) Application of bioisosteres in drug design. Literature Seminar 5: 7.

21. Meanwell NA (2011) Synopsis of some recent tactical application of bioisosteres in drug design. J Med Chem 54: 2529-2591.

22. Thomas Sander, Joel Freyss, Modest von Korff, Christian Rufener, DataWarrior (2015) An open-source program for chemistry aware data visualization and analysis. J Chem Inf Model 55: 460-473.

23. Wang X, Chen H, Yang F, Gong J, Li S, et al. (2014) iDrug: a web-accessible and interactive drug discovery and design platform. J Cheminform 6: 28 .

24. Chang KW, Tsai TY, Chen KC, Yang SC, Huang HJ, et al. (2011) iSMART an integrated cloud computing web server for traditional Chinese medicine for online virtual screening, de novo evolution and drug design. J Biomol Struct Dyn 29: 243-250.

25. Hartenfeller M, Schneider G (2011) De novo drug design. Methods Mol Biol 672: 299-323.

26. Villoutreix BO, Laconde G, Lagorce D, Martineau P, Miteva MA, et al. (2011) Tyrosine kinase syk non-enzymatic inhibitors and potential anti-allergic druglike compounds discovered by virtual and in vitro screening. PLoS One 6 : e21117.

27. Lipinski CA, LaMattina JL, Oates PJ (1986) Bioisosteric prototype design of biaryl imidazolyl and triazolyl competitive histamine $\mathrm{H} 2$-receptor antagonists. J Med Chem 29: 2154-2163.

28. Lalezari JP, Eron JJ, Carlson M, Cohen C, DeJesus E, et al. (2003) A phase II clinical study of the long-term safety and antiviral activity of enfuvirtide-based antiretroviral therapy. AIDS (London, England) 17: 691-698.

29. Siriwardena AN, Qureshi Z, Gibson S, Collier S, Latham M (2006) GPs' attitudes to benzodiazepine and 'Z-drug' prescribing: a barrier to implementation of evidence and guidance on hypnotics. Br J Gen Pract 56: 964-967. 